\title{
Prioritizing Invasive Plant Management Strategies
}

\author{
By Roger L. Sheley and Brenda S. Smith
}

$\mathrm{I}$ nvasive plants have many serious impacts on rangeland throughout the world. They can displace desirable species, alter the ecological function of the ecosystem, destroy wildlife habitat, decrease productivity, and facilitate frequent wildfires, with impacts costing billions of dollars annually. Major invasive plant management programs are established in most countries. Although a substantial effort to manage plant invasions is underway in the United States, the conservation benefits are questionable because these programs are expensive and risky to implement for the long term. Ecologically Based Invasive Plant Management (EBIPM) has the potential to provide an improved decision-making process, but managers are often uncertain about how to get started implementing this type of program.

Because invasive plant management is expensive and programs are often underfunded, it is critical to develop a simple method for prioritizing invasive plant management strategies. Careful allocation of scarce dollars is necessary. A simple tenet of such a prioritization would be to optimize the benefits from expenditures by gaining as much ecological and economic value for each dollar as possible. This requires managers to systematically implement the least costly, most successful, and most beneficial strategies progressively over time. Using this tenet, the more risky and more costly strategies are delayed until after the more effective solutions are fully implemented. Our purpose in this paper is to describe a process for prioritizing invasive plant management strategies, while implementing landscape-scale EBIPM.

\section{Cursory Mapping and Evaluation}

For many managers, the first step toward EBIPM is to conduct a cursory mapping survey to gain a general understanding of the location of invasive plants across the entire management area. This mapping can be initiated by simply querying local personnel to get an estimate of invasive plant species and their locations. Some on-the-ground confirmation of these locations might provide greater understanding of the reliability of the information. Map accuracy does not necessarily need to be high because, as management continues, maps should be continually amended and updated. For the purposes of prioritization, these maps only need to identify three basic conditions: 1) land that has no infestation or lightly scattered patches of invasive weeds (Figure 1);2) areas with a substantial infestation, but where there is enough desired vegetation growing in association with them to recover if the invasive plants are weakened or reduced (Figure 2); and 3) areas where the invasive weeds dominate in monocultures (Figure 3). One simple way of collecting relatively accurate data for maps is to use a sample mapping strategy and interpolating conditions between sample points. A number of mapping strategies are detailed in Establishing a Weed Prevention Area. ${ }^{1}$

\section{First Priority: Prevention}

To optimize costs/benefits, the highest priority is to focus prevention strategies on land identified as relatively invasive weed-free. Traditionally, management has focused on controlling invasive plants on already infested rangeland, whereas protecting noninfested rangeland has a lower priority. A proactive program focuses on systematic prevention; early control of newly arriving infestations provides positive economics returns. A single dollar spent on prevention can avoid 17 dollars in later expenses. ${ }^{2}$ The main components of programs aimed at preventing the invasion

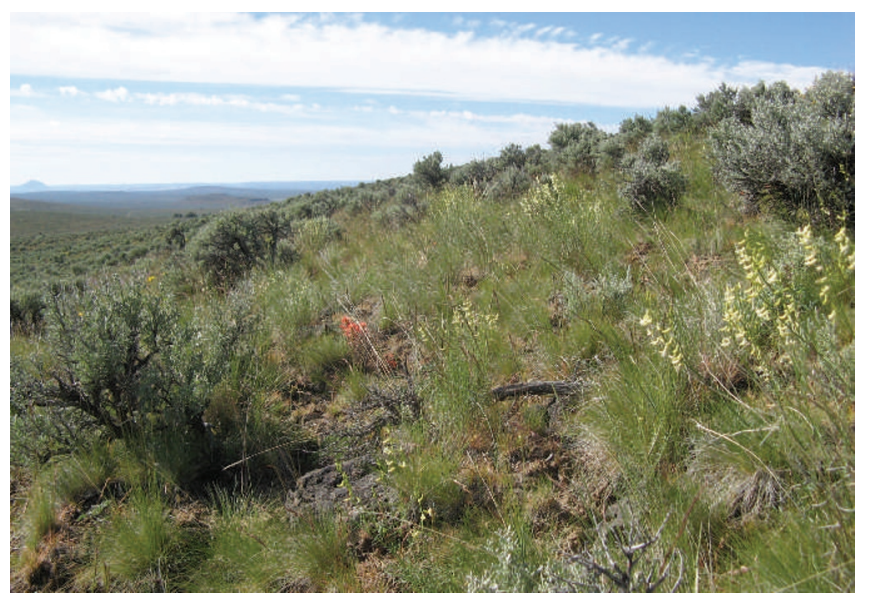

Figure 1. Land without infestation of invasive weeds. 


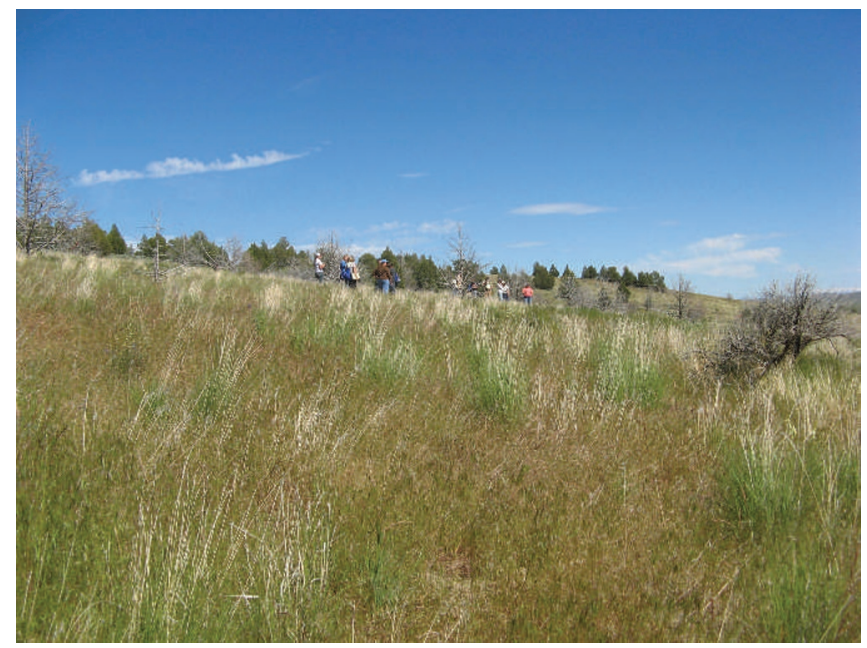

Figure 2. Areas with substantial infestations of invasive weeds but with desired vegetation still present.

of weeds include 1) minimizing invasive plant introduction into noninfested areas, principally by managing spread vectors; 2) early detection and eradication of small patches; and 3) increasing the resistance of desirable plant and soil communities to invasion.

The first priority in this process is to develop a comprehensive prevention plan (Figure 4). To develop this plan, we suggest implementing a Weed Prevention Area (WPA; see Ransom and Whitesides, "Proactive EBIPM: Establishing Weed Prevention Areas," this issue). Typically, a WPA is a partnership among neighboring landowners, usually within watersheds. Landowners work together to prioritize primary invasive weeds as key targets for prevention, and determine survey strategies for early detection and eradication efforts.

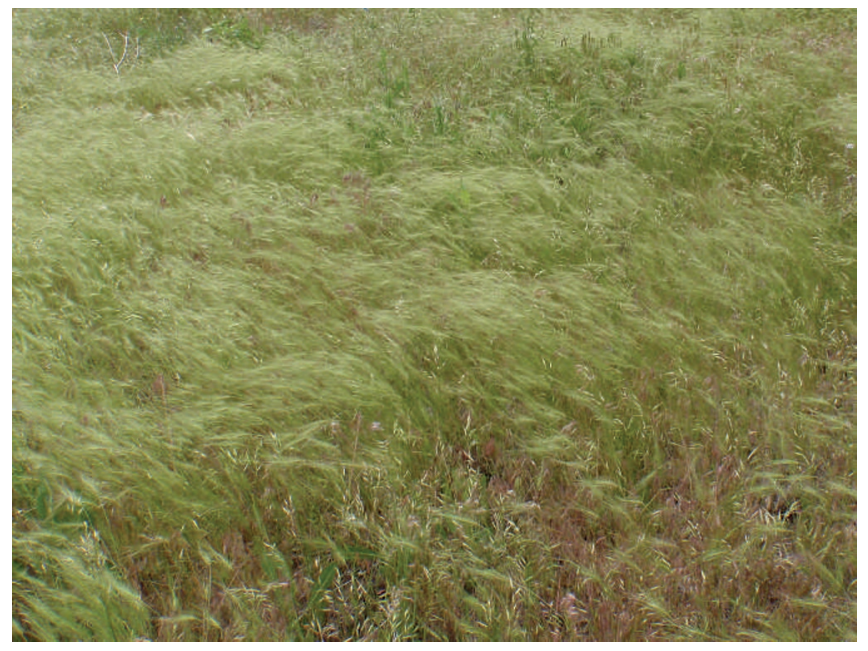

Figure 3. Invasive weeds dominating in a monoculture stand.

When a prevention program is implemented, repeated surveys are used to increase the accuracy of the original maps and to assess the effectiveness of the prevention program.

\section{Second Priority: Control}

During the invasion process, the abundance of weedy plants increases, and numbers of desirable plants decease over time. After a prevention program is implemented to protect uninfested lands, the second priority is to focus on partially intact ecosystems where enough desirable species generally exist to facilitate restoration after reducing the abundance of invasive plants. Although much of our work has been in sagebrush steppe ecosystems with infestations of invasive annual grasses, the prioritization process is applicable to most in-

\section{Table 1. EBIPM process-based framework}

\begin{tabular}{|l|l|l|}
\hline Causes of succession & Processes & Management factors \\
\hline Site availability & Disturbance & Size, severity, time intervals, patchiness \\
\hline \multirow{2}{*}{ Species availability } & Dispersal & Dispersal mechanisms and landscape features \\
\hline \multirow{2}{*}{ Species performance } & Propagule pool & Land use, disturbance interval, species life history \\
\hline & Resource supply & Soil, topography, climate, litter decomposition \\
\hline & Ecophysiology & Growth rate, photosynthesis, nutrient uptake \\
\hline & Life history & Allocation, reproduction timing and degree \\
\hline & Stress & Climate, site history, natural enemies \\
\hline
\end{tabular}




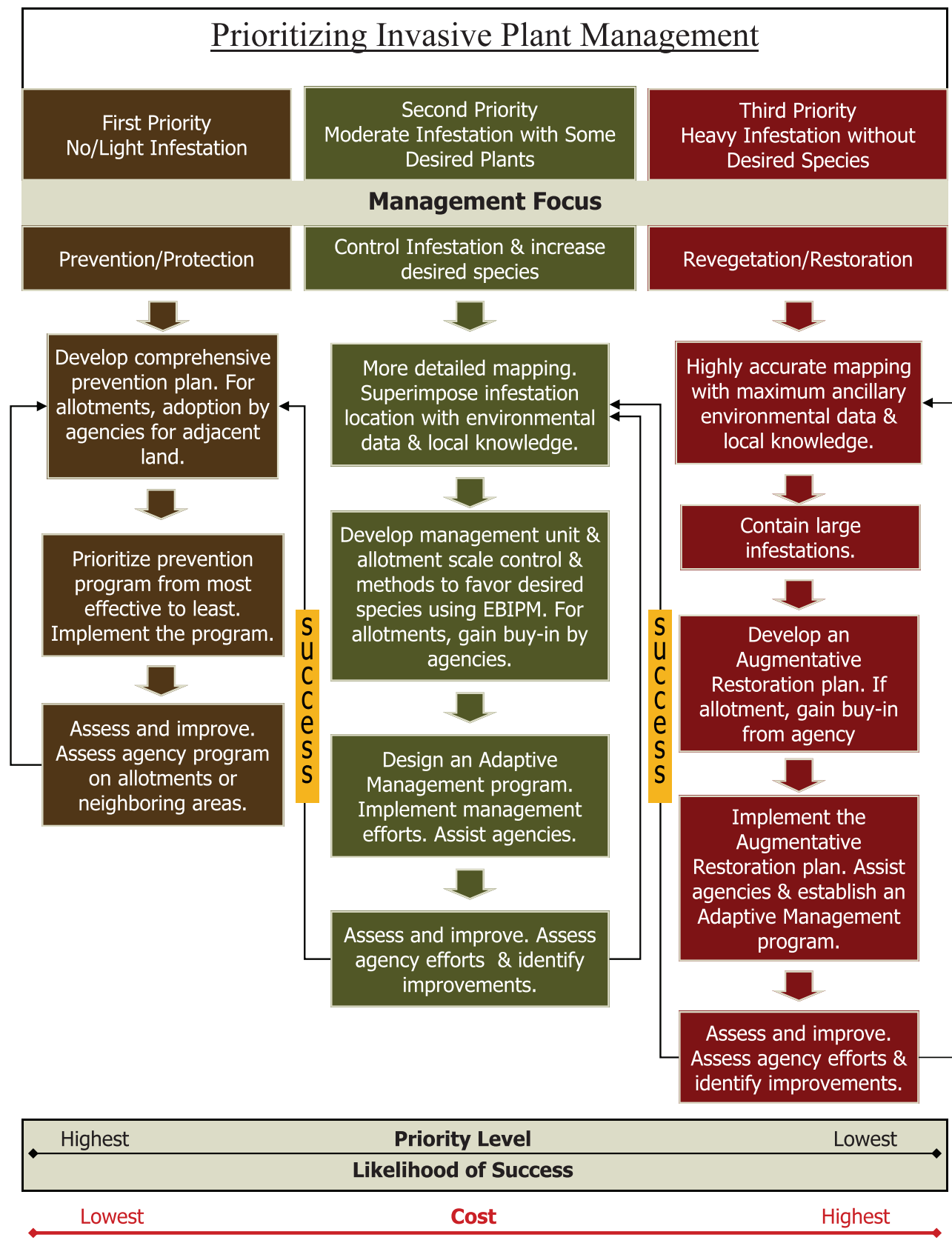

Figure 4. Flow chart for prioritizing invasive plant management efforts in an EBIPM program.

vasive plant infestations. These partially invaded systems are considered the second priority for management because costs and likelihood of success are moderate compared to prevention and restoration. Because some desired vegetation exists in the plant community, controlling invasive plants can facilitate dynamics toward the desired plants. It is often remarkable that desired species, even in very low abundance (10$15 \%$ cover) can reoccupy the plant community in response to a reduction in the vigor and abundance of invasive weeds.

Implementing effective control programs using the EBIPM process allows managers to focus on amending only those specific ecological processes in disrepair and whose repair is necessary to improve a particular situation (Table 1; see Sheley and Smith, "Ecologically Based Invasive Plant Management: Step by Step," this issue). Actions under a second priority include more detailed mapping and using the EBIPM assessment to identify those processes in disrepair. EBIPM also instructs managers to implement their program in a landscape-scale design to foster their ability to learn from and change their management as the process is ongoing.

In many cases, altering the competitive relationships between desired and invasive plants is a key to decreasing the abundance of weedy species and increasing the abundance of desired ones. For example, with invasive annual grass infesta- 
tions, commonly used methods for reducing their abundance are herbicides and grazing strategies that maximize impacts on and consumption of the invasive plants with minimal effects on desired grasses. Various herbicides are available for controlling invasive weeds, each having slightly a different spectrum of control. In many cases, fall applications control invasive annual grasses with minimal negative effects on perennial grasses which are dormant at that time. Repeated applications are often required for long-term control of invasive weeds, and over time desired perennial grasses increase if they were present at the onset of control.

Targeted grazing is also effective in controlling invasive plants, especially annual grasses. Managers can exploit the difference in plant phenologies, which create differences in palatability and nutritive value to animals. Invasive plants are most susceptible to damage by grazing while green. Perennial grasses are less palatable and more grazing tolerant when they are brown because they are dormant. This creates a natural opportunity to graze weeds when they are green and perennial grasses are brown. Once the perennial grasses initiate any growth, the animals must be moved to another pasture until the new growth becomes at least $25 \mathrm{~cm}$ (10 inchs) tall. Over time, desired perennial grasses will increase and annual grass abundance will decrease.

\section{Third Priority: Restoration}

The prioritization process places restoration of rangeland severely infested with invasive plants as the lowest priority for management, although containing the infestations to stop the spread should be a higher priority addressed in the prevention program. Initially, strategies to contain near monoculture stands will yield the best results. Containing populations requires decreasing dispersal by limiting seed availability. Limiting movement of animals through these infestations, and determining if a vegetative barrier to dispersal ${ }^{3}$ can be planted also are helpful.

On severely degraded landscapes, repairing ecological processes is critical to addressing the actual cause of invasion, rather than simply controlling weeds, which are a symptom. Restoration efforts are placed at low priority primarily because resources available for managing rangelands are almost always limited and restoration is expensive, plus it is notoriously difficult to achieve successful results. Principally, we want managers to first use their scarce dollars on implementing strategies to protect areas from infestations before moving on to more costly and more risky restoration strategies. There is value and justification for initiating small restoration research projects. Once managers have adequately addressed managing land under the first and second priorities, they will have tested strategies from which to build an EBIPM program.

The broad utility of a general EBIPM model (see Sheley and Smith, "Ecologically Based Invasive Plant Management:
Step by Step," this issue) ultimately depends on how well it enables managers to select appropriate tools and strategies in heterogeneous environments. Disturbance regimes, propagule pressure, and factors affecting plant performance vary substantially across the landscape. As a consequence, we can expect the three general drivers of plant community change also to vary within a single management unit. An effective EBIPM program needs to successfully incorporate this heterogeneity and allow managers to select and alter the appropriate combination of treatments as they move across the landscape. Once managers arrive at a point where restoration is being considered for management, adopting EBIPM strategies will improve probability of successful restoration efforts.

\section{Value of Prioritizing Management}

Managing rangeland is a complex endeavor that requires comprehensive and thoughtful decision making. Invasive plants increase the complexity of rangeland management and add major complexities to decision making. In addition, resources are becoming increasingly scarce and the need to optimize their use is ever-increasing. Managers can begin to optimize their resources by focusing on preventing new, noninfested areas from becoming invaded as their highest priority. Once the prevention program is in place and well-implemented, the second highest priority is to focus on areas where a portion of the desired plant community exists and can respond positively to invasive plant control. Areas of monocultures of invasive species are the most difficult and least likely conditions to restore and are the lowest priority for programs aimed at optimizing the use of scarce resources. EBIPM is a process aimed at repairing ecological processes that facilitate domination by undesirable species and provides a systematic method for achieving management goals and objectives.

\section{References}

1. Christensen, S., C. Ransom, R. Sheley, B. Smith, and R. Whitesides. 2011. Establishing a weed prevention area: a step by step user's guide. Burns, OR, USA: USDA-ARS. 40 p.

2. Offices of Technology Assessment of United States Congress. 1993. Harmful non-indigenous species in the United States. Washington, DC, USA: US Government Printing Office. $391 \mathrm{p}$.

3. Davies, K. W., A. M. Nafus, and R. L. Sheley. 2010. Nonnative competitive perennial grass impedes the spread of an invasive annual grass. Biological Invasions 12:3187-3194.

Authors are Rangeland Ecologist, roger.sheley@oregonstate.edu (Sheley) and Research Agronomist (Smith), USDA-ARS Eastern Oregon Agricultural Research Center, Burns, OR 97720, USA. USDA is an equal opportunity provider and employer. 